\title{
¿Nueva guerra energética? El escenario de Asia Central
}

\author{
Olga Uliánova
}

Con la salida de las tropas soviéticas de Afganistán y el fin de la Guerra Fría, la región de Asia Central dejó de ser un atractivo para los analistas internacionales y los medios de comunicación globales. Sin embargo, en la década de los noventa, vienen madurando importantes procesos en esta alejada zona continental de Eurasia: surgimiento de los nuevos estados independientes en lugar de las ex-repúblicas soviéticas - cada uno con sus particularidades étnicas, culturales y políticas, y con sus motivaciones de acción internacional- lo que ha cambiado el balance de fuerzas centroa" siático. La lucha interna en Afganistán tras la retirada de la Unión Soviética, ha adquirido el carácter de un conflicto interétnico entrecruzado con los de Asia Central ex-soviética. Los enormes recursos aún no explotados de petróleo y gas natural que posee la región, acrecientan su importancia para la política y economia mundiales del siglo xxI, comenzando desde ya la lucha por las fuentes de energía y canales de su exportación. La variable del petróleo se configura como el eje principal del conflicto centroasiático.

Desde que en febrero de 1989 el último soldado soviético abandonó Afganistán, este país, uno de los más pobres del mundo, perdido entre las cúspides más altas de Asia Central, desapareció de las páginas de periódicos y pantallas de televisión. Desde aquel entonces han pasado ya siete años, pero la paz aún no llega a sus sufridos parajes. La lucha interna en la que está sumido Afganistán hasta el día de hoy, aparece a primera vista como un caleidoscopio irracional de una guerra de todos contra todos, en la que un occidental no podría comprendernada. Pero en la práctica obedece en última instancia a intereses económicos y geopolíticos bien 
identificables, tales como el control sobre las rutas comerciales existentes y potenciales y, especialmente, sobre las eventuales vías de transporte de petróleo y gas.

Intentaremos desenredar el complejo ovillo centroasiático, identificando a los actores comprometidos y sus intereses.

Tradicionalmente la unidad estatal de Afganistán se basaba en una correlación compleja de intereses tribales, genéricos y de clanes de pushtunes (grupo étnico mayoritario en el país) y no-pushtunes (tadzhikos, uzbekos, turkmenos). Dentro de esta red, los elementos propiamente étnicos no siempre se encontraban en la primera plana y, por lo tanto, la existencia de los grupos étnicos similares en los paises vecinos (pushtunes en Pakistán, los demás en la Unión Soviética) no atentaba contra la unidad del país. Sin embargo, casi veinte años de guerras internas junto con la larga intervención militar soviética, socavaron el sistema tradicional de relaciones interétnicas en Afganistán.

Los vínculos comunitarios y de clanes se debilitaron, fortaleciéndose a la vez los vínculos de pertenencia étnica. El porcentaje de los pushtunes en la población se redujo producto de las pérdidas de las guerras y la emigración a Pakistán. Paralelamente creció el peso de otros grupos étnicos, en primer lugar de los tadzhikos.

La desaparición de la Unión Soviética y el surgimiento en la ex-Asia Central soviética de los estados independientes con diversos intereses geopolíticos, han cambiado profundamente la situación en torno a Afganistán. De hecho, hoy el país está dividido en tres partes: "Uzbekistán", "Tadzhikistán" y "Pushtunstán" afganos. Detrás de cada una de las fuerzas políticas y militares están una u otra fuerza externa.

\section{Pushtunstán.}

El Sur, Suroriente y Oeste del país (13 provincias en total con unos 7 millones de habitantes) está controlado por los pushtunes gobernados por el movimiento "Taliban" ("Estudiantado"). Encabezan el movimiento los jóvenes molas, hijos de la guerra que crecieron con el Corán y AKA en las manos. Las biografias de su líder Mojamed Omar y sus colaboradores más cercanos son extraordinariamente parecidas: decepcionados de la guerra tras la retirada soviética, se instalan en cierto momento en Pakistán y se dedican a la actividad religiosa, para resurgir luego en el mapa político afgano como partidarios de un estado islámico para Afganistán como panacea contra la eterna inestabilidad. ${ }^{\text {] }}$

${ }^{1}$ VerMoskovskie novosti, N880, 1995, p.15. 
Desde entonces, su base de operaciones es la antigua capital pushtuna Kandagar, cuya población, al igual que la de toda la región cansada de peleas interminables entre distintas bandas vinculadas al narcotráfico, los recibió como libertadores. Los talibos establecieron orden según las leyes de chariat: cortan brazos públicamente a los ladrones, prohilbieron televisión, música no religiosa, fútbol, obligaron alas mujeres ałisaryelo en la calle. Sin embargo, los éxitos de "Taliban" en asuntos laicos son mucho más modestos: en un año y medio de gobierno no hạ logradọponer en funcionamiento escuelas, hospitales, sistemas de agua potable y otros servicios públicos. ${ }^{2}$

Según los observadores, este orden dificilmente sería soportado en las regiones centrales de Afganistán, donde el islam nunca jugó un rol tan preponderante. No es casual que entre los líderes de otros grupos étnico-políticos no hay representantes del clero musulmán, pero sí militares, profesores universitarios y otros profesionales.

El éxito militar de los talibos que durante el año 1995 llegaron dos veces a las cercanias de Kabul se explica en primer lugar por el apoyo de Pakistán, el cual a su vez trata de resolver con su ayuda los problemas propios: primero, restablecer la estabilidad a lo largo de la carretera internacional que une Pakistán con los estados de Asia Central con la perspectiva de construcción de un gas y/o oleoducto por el mismo trayecto. No es casual que la primera ofensiva de talibos hacia Afganistán central comenzó tras el fracaso del contrato de suministro de algodón turkmeno a Pakistán, cuando las caravanas de camiones eran saqueadas regularmente en la carretera Ashjabad-Kvetta. ${ }^{3}$ Segundo, asegurar con las manos de los talibos la paz en la frontera afgano-pakistaní. Y, tercero, devolver a Afganistán millones de refugiados que complican las relaciones interétnicas en el mismo Pakistán. Además, los talibọs gozan del apoyo de la Arabia Saudita que los financia y de los Estados Unidos que ven en ellos un contrapeso a Irán que apoya el grupo tadzhiko de Rabbani-Masud establecido en Kabul.

\section{Uzbekistán Afgano.}

El Norte de Afganistán - su parte más desarrollada y poblada por uzbekos - está controlado por este grupo étnico liderado por Abdul Rashid Dustum. Sus 8 provincias donde se concentra entre el 5 y $10 \%$

\footnotetext{
${ }^{2}$ Obschaia gazeta, 4 de mayo, 1995.

${ }^{3}$ Izvestia, 23 de marzo, 1995.
} 
de la población del país se caracterizan por una mayor estabilidad con su administración propia, banca independiente de Kabul, escuelas y hospitales funcionando, y comercio floreciente. La región cuenta con grandes yacimientos de petróleo y gas para cuya explotación se han firmado recientemente acuerdos con empresas inglesas. 4

El líder de este cuasi-estado Abdul Rashid Dustum es uzbeko, proviene de una pobre familia campesina y estudió en una de las academias militares soviéticas. Durante el gobierno pro-soviético de Nadzhibula encabezó la policía y llegó a ser miembro del Comité Central del partido gobernante. En 1992, pasó al lado de la oposición y se convirtió en la fuerza principal del derrocamiento de Nadzhibula. Pronto se peleó con sus aliados tadzhikos y formó su estado propio en el Norte del país donde recibió la colaboración de varios ex-personeros del régimen de Nadzhibula, entre ellos el ex-Presidente Babrak Karmal, famoso por haber "llamado" a los soviéticos. El ejército de Dustum posee armamento modemo, incluidos tanques y avịones. En su capital actualmente hay más representaciones diplomáticas extranjeras que en Kabul. Ultimamente han mejorado mucho las relaciones con Gran Bretaña cuyos empresarios lograron la competencia por explotar los yacimientos petroleros de la región. Las relaciones con Uzbekistán independiente (ex-soviético) son muy buenas. La frontera entre ambos países está plenamente bajo el control mutuo. A la vez Dustum mantiene relaciones cuasi-oficiales con Rusia con una representación permanente en Moscú.

\section{Tadzhikistán Afgano.}

El centro del país poblado por el segundo grupo étnico de Afganistán - los tadzhikos - se encuentra en las manos del grupo liderado por Burjanuddin Rabbani y Ajmad Shaj Masud. Ellos controlan la capital del pais - Kabul - y 4 provincias del Noreste. La región cuenta con los yacimientos de esmeraldas más grandes del viejo mundo. Además, después de la toma de Kabul en abril de 1992, el grupo de Rabbani tiene bajo su control las reservas de oro del Banco Nacional de Afganistán.

Los líderes tadzhikos se destacan de otros caudillos por su alta alcumia y refinada formación. Asi, Ajmad Shaj Masud proviene de la antigua aristocracia militar afgana, estudió en el elitista liceo Istiklal en Kabul y la facultad de ingeniería de la Universidad de la misma ciudad. Después de la llegada del Shaj Daud al poder en 1973, Masud se refugió

${ }^{4}$ Moskovskie novosti, N99, 1996. 
en Pakistán. Durante los años de exilio recibió preparación militar en Irak, Libia, así como con los asesores norteamericanos en Pakistán. En la guerra por Kabul, después de la salida de las tropas soviéticas, mandó las unidades de élite, convirtiéndose posteriormente en el gobernador fáctico de la capital. Su base estratégica está constituida por las provincias de Pandzher en el oriente del país; ricas en lapislázuli y otras piedras preciosas y semipreciosas.

A diferencia de otros grupos étnicos presentes tanto en Afganistán como en la ex-Unión Soviética, los tadzhikos afganos superan con creces en número a sus connacionales en el Tadzhikistán independiente (ex-soviético). Esto permite a los lideres afganos-tadzhikos albergar los sueños de encabezar un "Gran Tadzhikistán" incorporando as sus dominios no sólo a la ex-república soviética del mismo nombre; sino importantes territorios de Uzbekistán ex-soviético, incluyendo las ciudades Samarcanda y Bujará.

Las autoridades de Kabul gozan del apoyo de Irán, basado en la similitud étnica de ambos grupos. ${ }^{5}$ Los talibos acusan también:a Moscú de guardar simpatías con el régimen de Rabbani-Masud, debido a las orientaciones históricas pro-rusas de ciertas familias aristocráticas afgano-tadzhikas. Por otro lado, la India que se caracteriza por una enemistad de largo tiempo y pretensiones territoriales mutuas con Pakistán, aparentemente está dispuesta a apoyar en Afganistán a los enemigos de sus enemigos. ${ }^{6}$

\section{Tadzhikistán Independiente.}

Tras la desaparición de la Unión Soviética el conflicto armado centroasiático se extendió al territorio de uno de los nuevos estados independientes de la región: Tadzhikistán. Durante los últimos cinco años este país ha vivido golpes de estado, cambios de presidentes y gobiernos, guerras civiles. Los mitines multidinarios en las plazas de grandes ciudades que se prolongan por días y semanas, diputados tomados como rehenes y combates de artillería pesada en barrios residenciales, constituyen el cuadro habitual de la vida política de esa nación.

En la base del conflicto encontramos las rivalidades regionales entre los clanes del Norte (de la zona del milenario Jodzhent, tradicionalmente más desarrollada de la región) que gobernaban Tadzhikistán tanto duran-

\footnotetext{
${ }^{5}$ Izvestia, 15 de mayo, 1995.

6 Nezavisimaia gazeta, 4 de enero, 1995.
} 
te su antigua indepeñdencia y bajo los zares rusos como en la época soviética, y las heterogéneas fuerzas del Sur montañoso del país estrechamente vinculado con la parte tadzhika de Afganistán.

La capital Dushanbe se encuentra en las manos del "Norte", el cual sin embargo no posee una fuerza bélica propia y es representado militarmente por una división rusa y pequeñas unidades de Kirguizia, Kazajstán y Uzbekistán que controlan los fragmentos correspondiëntes de la frontera afgana-tadzhika. Esta operación corresponde a la más grande presencia de las tropas rusas en el exterior en el periodo post-soviético. Por. otro lado, la oposición tiene sus bases en el territorio afgano y está dispuesta en el caso del triunfo a compartir el gobiemo de Dushanbe con Rabbani y Masud.

Frente a esta situación, la mayoría de los gobiernos de Asia Central ex-soviética, considera que la solución del conflicto pasa por un compiómiso entre el gobierno y la oposición, es decir entre los clanes regionales, en la repartición del poder en Tadzhikistán independiente. Uzbekistán espera en este caso jugar un rol de árbitro entre las partes en pugna, fortaleciendo su pósición de potencia subregional. Moscú mientras tanto sigue apoyando al gobiemo de Dushanbe, tratando de mantener intactas las fronteras de la antigua Unión Soviética, así como seguir controlando las importantes rutas comerciales desde el Caspio hacia el Noroeste de China. ${ }^{7}$ Sin embargo, la impopularidad de esta acción en la misma Rusia, junto con el desgaste de la táctica militar en vísperas de las elecciones, probablemente motivarán al gobierno de Yeltsin a revisar su política en Tadzhikistán.

\section{Petróleo.}

Intentaremos ahora echar una gota de petróleo sobre el mapa de Asia Central y veremos qué procesos políticos y económicos se revelan de esta manera en esta convulsionada región del mundo.

Hay que destacar que los yacimientos de petróleo y gas en la región que incluye la costa oriental del mar Caspio, en Kazajstán y Uzbekistán, junto con el Norte de Afganistán, se cuentan entre los más ricos en el mundo, a la vez que menos explotados. Aquéllos que se encuentran en el territorio de la ex-Unión Soviética comenzaron a explotarse en las últimas décadas y fueron unidos por un solo oleoducto con las regiones industriales del interior de la Unión Soviética. Los yacimientos en el

${ }^{7}$ Moskovskie novosti, 1996. 
territorio de Afganistán recién se están explorando. En la actualidad no existen vías de transporte que permitan sacar petróleo y gas de la región hacia los océanos esquivando el territorio de Rusia.

Mientras tanto, según la declaración del Viceministro norteamericano de Energía Bill White en mayo de 1995, "anualmente la demanda mundial crece en un mil millones de barriles al día, y de dónde vendrá este nuevo petróleo, dependerá tanto de la política, como de la geología" ${ }^{8}$ Esta creciente demanda internacional de petróleo acentuó la lucha por la herencia energética soviética, en la que participan hoy no sólo los gobiemos y las empresas estatales y privatizadas de Rusia y de los nuevos estados independientes, sino las principales transnacionales del rubro, junto con los gobiernos y empresas de los países a través de los cuales pueden pasar los nuevos óleo y gasoductos internacionales. Muchos de los conflictos armados en la zona petrolera de la ex-Unión Soviética y de sus vecinos están en una u otra forma relacionados con esta guerra energética.

Las inversiones en proyectos petroleros en la región crecen en progresión geométrica. Las compañías británicas se establecieron en el mar Caspio (British Petroleum), en sus costas (British Gas) y en el Norte de Afganistán (Alemy). Los franceses se insertan en Kazajstán y Uzbekistán. Los norteamericanos con la amplitud que los caracteriza trabajan en toda la región - desde la cuenca de Tarim en el Noroeste de China (Exson) hasta el Caspio (Mobil, Amoco, Texaco y otras). Con paso lento pero firme, avanzan hacia el Sur los gigantes rusos LUKoil(Caspio, Kazajstán) y Gasprom (Kazajstán). Los japoneses invierten en la infraestructura: construyen y reconvierten las refinerías y participan activamente en los grandiosos proyectos de los gasoductos transnacionales desde la Asia Central hacia las costas chinas. Un convenio de este tipo se firmó a mediados de 1995 en. Pekín entre las compañias Exson, Mitsubishi y la corporación nacional petrolera de China. El proyecto prevé la construcción de un gasoducto de cerca de 8 mil $\mathrm{km}$. desde Turkmenia hasta las costas del Pacífico. ${ }^{9}$

\section{Comunicaciones energéticas.}

Precisamente las comunicaciones constituyen el nudo de los problemas de explotación de petróleo y gas en esta región profundamente continen-

\footnotetext{
${ }^{8}$ Nowie vremia, N6, 1995.

${ }^{9}$ Kommersant Dayly, 13 de octubre, 1995.
} 
tal. Como señalamos más arriba, en la actualidad existen sólo un oleoducto y un gasoducto que vinculan Asia Central con el mundo, y se dirigen a través del territorio de Uzbekistán hacia el interior de Rusia.

En la situación más paradojal se encuentra Kazajstán, que posee grandes yacimientos petroleros y de gas en el Oeste de la república comunicados con las refinerías y óleo y gasoductos de la zona del Volga en Rusia, y las refinerías en el Norte y Este que reciben el petróleo siberiano. Producto de esta situación, Kazajstán que produce y refina petróleo en grandes cantidades no puede autoabastecerse de combustible al margen de Rusia.

Por otro lado, Uzbekistán se convierte en una especie de árbitro en los conflictos centroasiáticos, chantajeando a sus vecinos con cerrar los pasadores de los gasoductos. El mismo Presidente uzbeko Islam Karimov se pronunció muy francamente al respecto: " $\mathrm{Si}$ se habla del dictado o del predominio de Uzbekistán, hay que recordar que la comunicación entre las repúblicas, quiéranlo o no, pasa de todas formas a través de Uzbekistán".

Es fácil de comprender, por lo tanto, por qué el centro de gravedad en la lucha por los recursos energéticos de Asia Central se traslada paulatinamente a la esfera de las comunicaciones. A comienzos del año 1996, ya existían cerca de 20 proyectos de nuevos gaso y oleoductos internacionales.

Al calor de esta competencia en Asia Central y a su alrededor comienzan a perfilarse las nuevas alianzas petroleras. De hecho, las alternativas de exportación de los recursos de la región no son muchas. Asia Central está encerrada entre tres potencias: Rusia, China e Irán. Afganistán, junto con el Cáucaso, constituyen dos corredores geopolíticos de enorme importancia. La lucha por el poder allí en estos momentos es por el trazado y control de los futuros óleo y gasoductos desde una de las regiones potencialmente más ricas en estos recursos.

La debilidad de los sistemas institucionales de los nuevos estados independientes en la territorio de la ex-Unión Soviética y de los cuasiestados en el territorio de Afganistán, su vulnerabilidad a las influencias externas recompensan para las transnacionales las incomodidades de inestabilidad política y conflictos armados en la región. Como se pronunciara al inicio de la ofensiva centroasiática en 1993 el director general de la compañía francesa Elf Aquitaine, Flosh-Prigean, "las compañías petroleras poseen su propia lógica. No nos importan los regímenes políticos y religiosos, y la posibilidad del derrumbe de los estos centroasiáticos no nos asusta mucho. Lo único a lo que nosotros tenemos miedo 


\section{O. Uliánova / ¿Nueva guetra energética? (noticias ...}

es a la modificación de la politica tributaria... Las compañías petroleras hoy huyen de California, donde no hay peligro de influencia iraní, pero donde fue revisada la legislación tributaria". 10

\section{Bloques.}

De hecho, actualmente en Asia Central se observa una competencia aguda entre dos bloques. Por un lado, Rusia, Turkmenia, Tadzhikistán, India y el régimen de Kabul. Por otro lado, Uzbekistán, Pakistán, los talibos y Dustum, apoyados por los Estados Unidos y Europa Occidental.

En este sentido, adquiere un significado especial la mencionada ofensiva de los talibos hacia el Noroeste de Afganistán y sus esfuerzos por poner bajo su control la ruta que va desde Kushka (Turkmenia) vía Guerat y Kandagar hasta Kvetta (Pakistán). En el montañoso país, esta antigua ruta comercial podria convertirse en el mejor lecho natural para la exportación del petróleo de Turkmenia y de la zona del Caspio en general hacia las costas de Pakistán. No es casual que inmediatamente después de la toma de Guerat por los talibos, el Presidente paquistaní Faruk Legari visitó la capital de Turkmenia, Asjabad, donde presentó el proyecto de gasoducto Turkmenia-Afganistán-Paquistán. Dos semanas después, los Estados Unidos suavizaron las sanciones en contra de paquistán establecidas en 1990.

Por otro lado, una eventual frontera directa entre los territorios de los talibos y de Dustum permitiría canalizar en la misma dirección tanto el petróleo de esta región uzbeka-afgana, como del Uzbekistán ex-soviético. Esta idea encuentra una plena comprensión de las autoridades de Tashkent.

A estos planes se les opone el ardiente deseo de Rusia e India de no permitir desviar el petróleo y gas de la región hacia Paquistán. Kazajstán y Kirguizia tratan de maniobrar entre estas dos alianzas, fortaleciendo a la vez sus vínculos con los países de la cuenca del Pacífico. China, de acuerdo a su tradición, espera observando la pelea de dos tigres.

Por supuesto, estos bloques tienen carácter provisional, táctico, ya que agrupan a veces a los potenciales competidores. Sin embargo, el factor energético influye cada día más en el clima geopolítico general en la región. Y cada día en mayor grado determina la política de las potencias en Asia Central.

\footnotetext{
${ }^{10}$ Nezavisimaia gazeta, 11 de julio, 1993.
} 


\section{ESTUDIOS INTERNACIONALES}

Sin embargo, ni siquiera los conflictos actuales en la lucha por la herencia energética postsoviética justifican ciertos pronósticos apocalípticos que aparecen de vez en cuando en la prensa europea y rusa. Lo más probable es que esta lucha no va a tener un ganador único: los óleo y gasductos irán simultáneamente en varias direcciones y la presión que se está acumulando en la cerrada caldera de Asia Central inevitablemente descenderá. 